\title{
Cardiometabolic results from an armband-based weight loss trial
}

This article was published in the following Dove Press journal: Diabetes, Metabolic Syndrome and Obesity:Targets and Therapy 28 May 2011

Number of times this article has been viewed

\author{
John C Sieverdes \\ Xuemei Sui \\ Gregory A Hand \\ Vaughn W Barry \\ Sara Wilcox \\ Rebecca A Meriwether \\ James W Hardin \\ Amanda C McClain \\ Steven N Blair \\ Department of Exercise Science, \\ University of South Carolina, \\ Columbia, SC, USA
}

Correspondence: John C Sieverdes

921 Assembly Street, Suite 212

Columbia, SC 29208, USA

Tel +l 8032405790

Fax + I 8037772504

Email sieverdj@email.sc.edu
Purpose: This report examines the blood chemistry and blood pressure (BP) results from the Lifestyle Education for Activity and Nutrition (LEAN) study, a randomized weight loss trial. A primary purpose of the study was to evaluate the effects of real-time self-monitoring of energy balance (using the SenseWear ${ }^{\mathrm{TM}}$ Armband, BodyMedia, Inc Pittsburgh, PA) on these health factors.

Methods: 164 sedentary overweight or obese adults $\left(46.8 \pm 10.8\right.$ years; BMI $33.3 \pm 5.2 \mathrm{~kg} / \mathrm{m}^{2}$; $80 \%$ women) took part in the 9-month study. Participants were randomized into 4 conditions: a standard care condition with an evidence-based weight loss manual $(n=40)$, a group-based behavioral weight loss program $(n=44)$, an armband alone condition $(n=41)$, and a group plus armband $(n=39)$ condition. BP, fasting blood lipids and glucose were measured at baseline and 9 months.

Results: 99 participants (60\%) completed both baseline and follow-up measurements for BP and blood chemistry analysis. Missing data were handled by baseline carried forward. None of the intervention groups had significant changes in blood lipids or BP when compared to standard care after adjustment for covariates, though within-group lowering was found for systolic BP in group and group + armband conditions, a rise in total cholesterol and LDL were found in standard care and group conditions, and a lowering of triglycerides was found in the two armband conditions. Compared with the standard care condition, fasting glucose decreased significantly for participants in the group, armband, and group + armband conditions (all $P<0.05$ ), respectively

Conclusion: Our results suggest that using an armband program is an effective strategy to decrease fasting blood glucose. This indicates that devices, such as the armband, can be a successful way to disseminate programs that can improve health risk factors. This can be accomplished without group-based behavioral programs, thereby potentially reducing costs.

Keywords: armband, energy balance, randomized controlled trial, physical activity, blood lipids, blood glucose

\section{Introduction}

Prior reports of participation in physical activity (PA) interventions ${ }^{1-5}$ have observed favorable changes in physiological risk factors. These reports led to the 2008 publication of the "Physical Activity Guidelines for Americans," which documents that most health benefits result from at least 150 minutes of moderate activity a week, 75 minutes of vigorous activity a week, or a combination of the two along with two or more days of muscle-strengthening activities that work all major muscle groups. ${ }^{6}$ Risk factors such as elevated levels of blood pressure (BP), blood lipids, and glucose play an important role in determining risk of developing chronic diseases or death. ${ }^{7-11}$ Prior PA intervention 
studies using technology tools (eg, pedometers) have used paper-based materials, such as in the First Step Program, ${ }^{12}$ or have used groups to teach cognitive and behavioral strategies to increase PA. ${ }^{13}$ Fewer studies have utilized technologybased approaches to promote weight loss and PA. ${ }^{14-18}$ It is important to examine new methods using the latest technology to provide feedback to participants in a study that is readily available, and flexible to their goals. The ability to use real-time feedback monitoring of energy expenditure may be a useful strategy to enable success in a wide variety of populations through its interactive nature, and must be studied more closely.

To our knowledge, relatively few randomized controlled trials (RCT) have examined technology-based weight loss approaches to improve BP, blood lipids, and glucose. ${ }^{12,14,16,17,19,20}$ The Lifestyle Education for Activity and Nutrition (LEAN) study was a 9 month RCT to determine the effectiveness of using the SenseWear ${ }^{\mathrm{TM}}$ Armband (BodyMedia, Inc Pittsburgh, PA) for weight loss among 164 sedentary and overweight or obese individuals. While weight loss was the primary outcome of LEAN, BP, blood lipids, and fasting glucose were a priori secondary outcomes. ${ }^{21}$ The LEAN study provided an opportunity to examine the effects of various weight loss approaches on these selected cardiometabolic factors. Therefore, the primary aim of this report was to examine changes in BP, fasting blood lipids, and fasting glucose across different intervention conditions. Findings from this study will further our understanding of utilizing real-time self-monitoring devices on physiological outcomes. ${ }^{19}$

\section{Methods}

\section{Study design}

A complete description of the LEAN study design and methods appears elsewhere. ${ }^{21}$ In brief, the study was a RCT with a standard care control condition and 3 treatment conditions. The treatment conditions consisted of a group behavioral change intervention based on the transtheoretical model and social cognitive theory ${ }^{22}$ (group), an armband alone condition (armband), and a combined group-based weight loss intervention and armband condition (group + armband). The research protocol was reviewed and approved annually by the University of South Carolina Institutional Review Board. Written informed consent was obtained from all participants.

\section{Study participants}

Thorough descriptions of the recruiting and screening processes, as well as the methods are available. ${ }^{21}$ Briefly, the study was limited to men and women aged 18 to 65 years who were sedentary (not accumulating 150 minutes of moderate to vigorous PA throughout the week in bouts $\geq 10$ minutes), overweight or obese (body mass index [BMI] between $25.0-45.0 \mathrm{~kg} / \mathrm{m}^{2}$ ), and with access to the internet. Exclusion criteria included significant weight loss $(>20 \mathrm{lbs})$ in the prior 6 months; elevated BP ( $\geq 160 / 95 \mathrm{~mm} \mathrm{Hg}$ ); current participation in a formal weight loss program; using medications that affect weight; and ailments, medical conditions or other issues (eg, pregnancy) that limit PA or would prevent participants from adhering to the protocol. Individuals with a score of 16 or more on the Center for Epidemiological Studies Depression scale were excluded based on data from other studies demonstrating that depressed mood is associated with attrition from weight loss programs. ${ }^{23}$ Participants were recruited from the greater Columbia, South Carolina area from February 2008 to January 2009.

\section{Outcomes}

All LEAN study staff were trained by the same supervisor to minimize inter-technician variability. Blood lipids and glucose were measured at baseline and 9-month assessment visits. Participants were instructed to fast (ie, no food or drink after midnight, besides water) for these assessments. All blood draws occurred between 7.00 am and 9.30 am and were taken from the antecubital vein. Serum samples were processed and analyzed using standardized procedures by a Versamax microplate reader (Molecular Devices, Inc, Sunnyvale, CA) using Pointe Scientific, Inc (Canton, MI) reagents and standards, to measure total cholesterol (TC), high-density lipoprotein (HDL), and triglycerides. Very-lowdensity lipoprotein (VLDL) was first calculated by dividing the triglyceride count by 5 . Then the following equation was used to calculate low-density lipoprotein (LDL):

$$
\mathrm{TC}-\mathrm{HDL}-\mathrm{VLDL}=\mathrm{LDL}
$$

Three supine readings of BP were taken alternately after a 5-minute supine resting period and averaged. BP was measured using calibrated mercury sphygmomanometers following the JNC7 protocol. ${ }^{24}$

\section{Other measures}

Body weight to the nearest $0.25 \mathrm{lbs}$ was assessed using a calibrated balance-beam scale. Height to the nearest 16 th of an inch was assessed using a wall-mounted stadiometer. Smoking history and medication use were assessed by responses on detailed medical history questionnaires and reviewed by a physician. 


\section{Intervention}

Participants were randomly assigned to either the standard care control condition or to one of the intervention conditions: group, armband, or group + armband.

Standard Care: These participants received a self-directed weight loss manual based on two evidence-based programs, Active Living Every Day (ALED) ${ }^{25}$ and Healthy Eating Every Day (HEED).$^{26}$ The manual's focus was to help individuals adopt healthful eating patterns and increase their PA levels. Cognitive and behavioral strategies consistent with the transtheoretical model and social cognitive theory were emphasized. ${ }^{27,28}$ All study participants received this manual. Group: During the 9-month intervention, participants received 14 group sessions during the first 4 months, then 6 one-onone telephone counseling sessions over the final 5 months. Each group session followed the ALED and HEED curriculum format from the manual, with the addition of a weekly weigh-in and more content directly related to weight loss. The one-on-one telephone counseling sessions were designed to promote the maintenance of behavior change.

Armband: The armband condition received the SenseWear ${ }^{\mathrm{TM}}$ platform consisting of the SenseWear ${ }^{\mathrm{TM}}$ Armband, a wrist watch with real-time display, and access to a personalized Weight Management Solutions web account. While wearing the armband and wrist watch display, participants received real-time feedback on several outcomes (ie, energy expenditure, minutes spent in moderate and vigorous PA, steps per day, progress towards goals). Feedback could be reviewed graphically (eg, energy intake, energy balance, and weight loss) as participants regularly downloaded their PA data and recorded daily energy intake and body weight to the Weight Management Solutions web account. Participants were asked to wear the armband at least 16 hours a day, 7 days a week.

Group + Armband: These participants received all components of the group condition with the addition of the SenseWear ${ }^{\mathrm{TM}}$ platform in the armband condition.

\section{Participant retention, adherence, blinded assessment, and randomization}

To facilitate retention and adherence, participants completed a 2-week pre-randomization run-in period and received a printed list of study requirements and expectations. Participants were compensated for completion of the baseline and month 4 assessment (US \$10) and month 9 assessment (US \$15), totaling US \$25. Assessment personnel were blinded to intervention assignment. Participants were reminded not to discuss their condition assignment with the assessment team. Randomization assignment was computer generated and conducted by the statistician.

\section{Statistical analysis}

Descriptive baseline characteristics for conditions were tabulated as means and standard deviations (SD) or as percentages. Differences in blood chemistry and BP changes within and across conditions were tested by analysis of covariance with adjustment for baseline age, gender, race, education, recruitment wave, and baseline lipid values. Furthermore, BP and lipid measures were adjusted for baseline medications affecting the respective outcomes. An $\alpha$ level of 0.05 was used because it was an a priori intention to compare only the differences between the intervention conditions and the standard care condition. ${ }^{21}$ Results are presented as adjusted means with standard error (SE) or 95\% confidence intervals (CI).

For comparison, all outcomes were tested using only available data, without using baseline values carried forward for missing follow-up data. The results from these analyses did not differ substantially from the analyses with baseline values carried forward. For presentation herein, we report the baseline observation carried forward analyses using SAS statistical software, version 9.2 (SAS Inc, Cary, North Carolina).

\section{Results}

A total of 787 telephone screening calls were completed. Based on exclusion and inclusion criteria, 590 potential participants (75\%) were ineligible (Figure 1). After giving informed consent, 197 (25\%) were randomized, of whom $164(83 \%)$ had complete data at baseline. One hundred and four $(63 \%)$ completed the study with 99 providing usable follow-up data $(60 \%)$. Baseline values were carried forward for missing data or dropouts, so data from 164 of 197 participants $(83 \%)$ were included in the primary analyses.

The mean age was $47.6 \pm 10.7(\mathrm{SD})$ years and mean BMI $33.2 \pm 5.3$ (SD) $\mathrm{kg} / \mathrm{m}^{2}$ for the participants in the study population, with $31.1 \%$ being African American (Table 1). About a third (31.1\%) of the participants took medication for hypertension, and $26.8 \%$ were currently prescribed lipid lowering medication. Very few participants were taking medication for high blood glucose (7.3\%). Only $4.9 \%$ of participants were current smokers, and a high percentage of participants $(77.4 \%)$ were college graduates. Cardiovascular risk factors were within normal ranges.

Table 2 presents the changes in BP and lipid variables. Compared with the standard care condition, none of the 


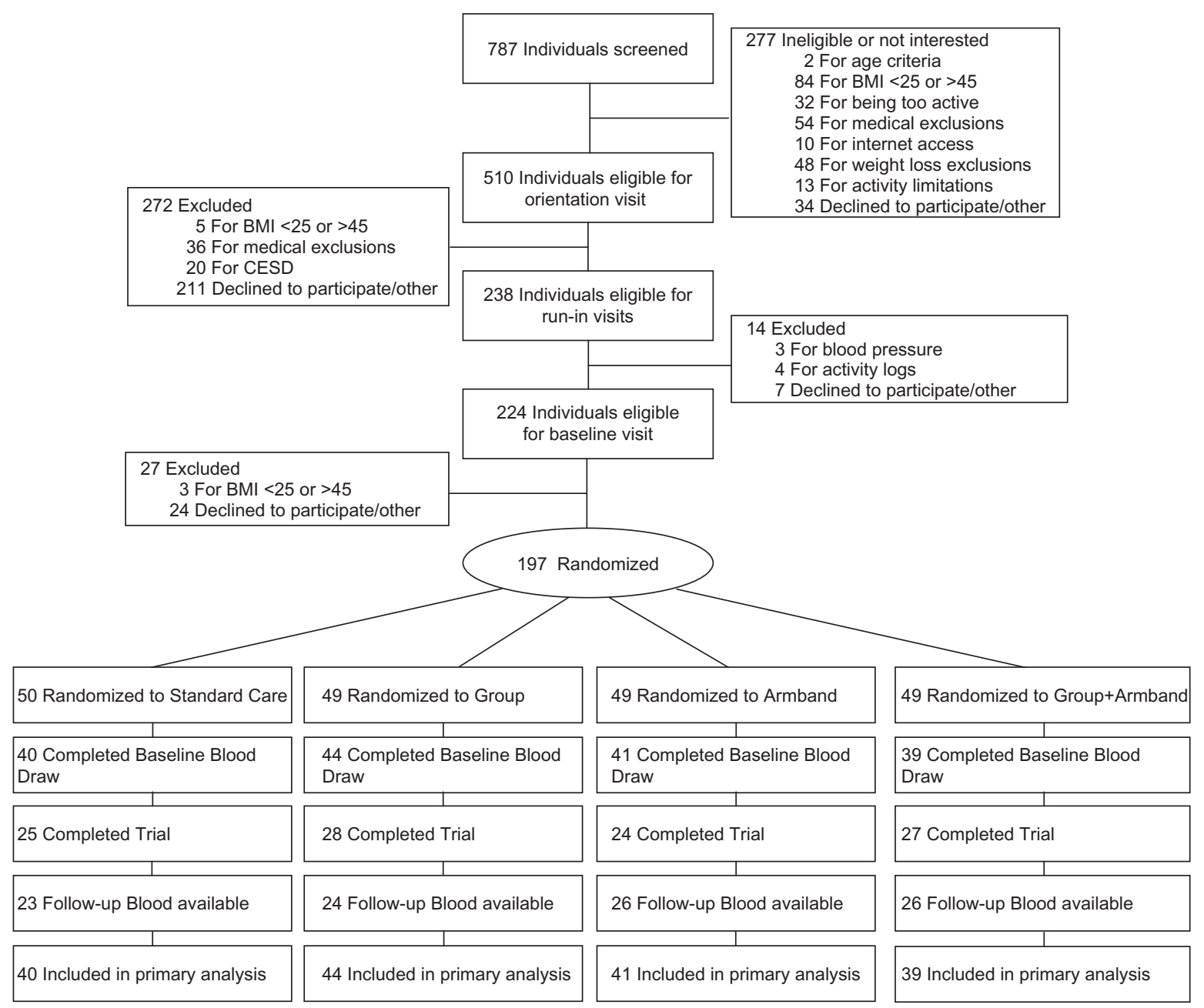

Figure I Consolidated Standards of Reporting Trials (CONSORT) diagram describing recruitment and retention of participants. If follow-up blood chemistry were missing, baseline values were carried forward.

intervention conditions had significant changes in BP or lipids in analyses adjusted for baseline value, age, gender, race, education, medication, and recruitment wave. When groups were stratified by medication, these results did not differ (data not shown). Lower systolic blood pressures were found within the group $(-2.96 \mathrm{~mm} \mathrm{Hg})$ and group + armband $(-3.48 \mathrm{~mm}$ $\mathrm{Hg}$ ) conditions (all $P<0.05$ ). Significant within-group increases of TC and LDL were found in standard care (TC change, $18.32 \mathrm{mg} / \mathrm{dL}$; LDL change, $15.84 \mathrm{mg} / \mathrm{dL}$ ) and group (TC change, $15.58 \mathrm{mg} / \mathrm{dL}$; LDL change, $13.71 \mathrm{mg} / \mathrm{dL}$ ) conditions, respectively (all $P<0.05$ ). There were also significant within-group decreases in triglycerides in both the armband $(-13.07 \mathrm{mg} / \mathrm{dL})$ and group + armband $(-19.87 \mathrm{mg} / \mathrm{dL})$ conditions (all $P<0.05$ ).

Figure 2 shows the mean change for fasting glucose for all conditions. Due to the low number of participants taking medication for blood glucose $(n=12)$, those persons were excluded, leaving 152 in the analysis. All values represent the least-squares means adjusted for age, gender, race, education, recruitment wave, and baseline glucose level. Compared with the standard care condition, mean glucose decreased by $5.42 \mathrm{mg} / \mathrm{dL}$ in the group condition, $8.88 \mathrm{mg} / \mathrm{dL}$ in the armband condition, and $12.59 \mathrm{mg} / \mathrm{dL}$ in the group + armband condition. Pairwise comparisons between standard care and group, armband, and group + armband conditions were significant $(P<0.05)$.

\section{Discussion}

The primary finding from this RCT was a favorable reduction in fasting glucose in the treatment conditions. All treatment conditions showed a significant reduction when compared with the standard care condition. Only within-group conditions for group and group + armband were found for lower blood pressure. Other changes included within group lowering of triglycerides for the armband and group + armband treatments. Though not anticipated, the standard care and group treatments had unexpected higher TC and LDL values 
Table I Baseline characteristics*

\begin{tabular}{|c|c|c|c|c|c|}
\hline Characteristics & $\begin{array}{l}\text { Total } \\
(n=164)\end{array}$ & $\begin{array}{l}\text { Standard care } \\
(n=40)\end{array}$ & $\begin{array}{l}\text { Group } \\
(n=44)\end{array}$ & $\begin{array}{l}\text { Armband } \\
(n=4 I)\end{array}$ & $\begin{array}{l}\text { Group }+ \text { Armband } \\
(n=39)\end{array}$ \\
\hline Age (years) & $47.6(10.7)$ & $47.8(9.0)$ & $46.8(12.4)$ & $49.2(11.4)$ & $46.6(9.6)$ \\
\hline Female, No. (\%) & $132(80.5)$ & $33(82.5)$ & $35(79.6)$ & $32(78.1)$ & $32(82.1)$ \\
\hline African American, No. (\%) & $5 I(3 I . I)$ & $15(37.5)$ & $13(29.6)$ & $12(29.3)$ & II (28.2) \\
\hline College degree or & $127(77.4)$ & $31(77.5)$ & $35(79.6)$ & $32(78.1)$ & $29(74.4)$ \\
\hline \multicolumn{6}{|l|}{ higher, No. (\%) } \\
\hline Body mass index $\left(\mathrm{kg} / \mathrm{m}^{2}\right)$ & $33.2(5.3)$ & $33.9(5.6)$ & $32.8(4.9)$ & $33.4(5.7)$ & $32.7(5.0)$ \\
\hline \multicolumn{6}{|c|}{ Resting blood pressure (mmHg) } \\
\hline Systolic & $127(12)$ & $129(13)$ & $126(\mathrm{II})$ & $129(13)$ & $125(12)$ \\
\hline Diastolic & $81(8)$ & $82(9)$ & $79(8)$ & $81(8)$ & $79(7)$ \\
\hline \multicolumn{6}{|l|}{ Fasting plasma lipids (mg/dL) } \\
\hline Total cholesterol & I $73.3(44.2)$ & $17 \mid .8$ (34.2) & $170.8(48.3)$ & I78.I (47.5) & I72.5 (46.I) \\
\hline HDL & $47.8(19.4)$ & $48.5(20.3)$ & $47.5(18.8)$ & $45.4(19.5)$ & $50.2(19.4)$ \\
\hline LDL & $105.5(42.5)$ & $102.5(33.0)$ & $103.2(46.2)$ & I I I.2 (45.2) & $105.2(44.8)$ \\
\hline Triglycerides & $99.6(64.9)$ & $103.9(67.7)$ & $100.6(66.5)$ & $107.6(7 \mid .5)$ & $85.6(51.6)$ \\
\hline Fasting blood glucose (mg/dL) & $97.7(24.8)$ & 99.1 (18.3) & $104.0(29.6)$ & $98.0(21.9)$ & $88.8(26.0)$ \\
\hline Current smoker, No. (\%) & $8(4.9)$ & $4(10)$ & I (2.3) & $2(4.9)$ & I (2.6) \\
\hline \multicolumn{6}{|l|}{ Current medication, No. (\%) } \\
\hline Hypertension & $5 I(3 I . I)$ & II (27.5) & II (25.0) & $16(39.0)$ & $13(33.3)$ \\
\hline Diabetes mellitus & $12(7.3)$ & I (2.5) & $5(1 \mathrm{I} .4)$ & $4(9.8)$ & $2(5.1)$ \\
\hline Lipids lowering medication ${ }^{\dagger}$ & $44(26.8)$ & 7 (I7.5) & $13(29.6)$ & $15(36.6)$ & $9(23.1)$ \\
\hline
\end{tabular}

Notes: *Data presented as mean (standard deviation) unless otherwise indicated. †Lipids lowering medication includes Statin and triglycerides-medications. Abbreviations: HDL, high-density lipoprotein; LDL, low-density lipoprotein.

SI conversions: To convert LDL and HDL to $\mathrm{mmol} / \mathrm{L}$, multiply by 0.0259 ; triglycerides to $\mathrm{mmol} / \mathrm{L}$, multiply by $0.01 \mathrm{I} 3$; fasting glucose to mmol/L, multiply by 0.0555 .

after 9 months. We speculate that this may have resulted from a change or discontinuation of medications, not following the fasting procedures, body weight changes, or other unknown causes. No differences were found between the group intervention, the armband alone, or a combination of the two on glucose. Overall, these findings suggest that a technologybased intervention with an armband, used as a real-time self-monitoring device, is a sufficient behavior change strategy for reducing fasting blood glucose after 9 months.

\section{Comparison to other studies}

Several studies incorporating technology-based devices using real-time feedback in their behavioral change strategies have focused on PA and weight changes in their designs. ${ }^{15,18}$
Few studies have included cardiometabolic changes. $12,14,16,17,19,20$ Of these, an internet-based RCT using Active Living Every Day (ALED) and pedometers found reductions in triglycerides $(P=0.01)$ and slight reductions in LDL and TC, resulting in a lower coronary risk ratio (CRR). Fasting glucose in this 16 week study did not change $(P=0.92) \cdot{ }^{14}$ Our study followed participants for a substantially longer time period, which could account for the reduction in blood glucose measures. In the First Step Program (FSP), a pedometer-based intervention, 47 overweight/obese sedentary individuals increased their activity at 16 and 24 weeks, but no significant changes were noted for glycemia, BP, or cholesterol values. ${ }^{12}$ In a study by de Greef et al, ${ }^{16} 41$ type 2 diabetics were randomized to a control group or an intervention group consisting of 5 group

Table 2 Change in blood pressure and lipids*

\begin{tabular}{|c|c|c|c|c|c|}
\hline Characteristics & $\begin{array}{l}\text { Standard care } \\
(n=40)\end{array}$ & $\begin{array}{l}\text { Group } \\
(n=44)\end{array}$ & $\begin{array}{l}\text { Armband } \\
(n=4 I)\end{array}$ & $\begin{array}{l}\text { Group + armband } \\
(n=39)\end{array}$ & P-Value ${ }^{\dagger}$ \\
\hline Change in resting systolic $\mathrm{BP}(\mathrm{mm} \mathrm{Hg})$ & $0.57(1.18)$ & $-2.96(1.12)^{\ddagger}$ & $-2.24(1.16)$ & $-3.48(1.20)^{\ddagger}$ & 0.08 \\
\hline Change in resting diastolic $\mathrm{BP}(\mathrm{mm} \mathrm{Hg})$ & $-0.01(0.79)$ & $-0.42(0.75)$ & $-0.83(0.78)$ & $-1.4 \mid(0.80)$ & 0.64 \\
\hline Change in total cholesterol $(\mathrm{mg} / \mathrm{dL})$ & $18.32(5.57)^{\ddagger}$ & $15.58(5.28)^{\ddagger}$ & $3.06(5.50)$ & $3.61(5.62)$ & 0.11 \\
\hline Change in HDL $(\mathrm{mg} / \mathrm{dL})$ & $2.66(2.63)$ & $3.28(2.50)$ & $3.52(2.60)$ & $3.33(2.66)$ & 1.00 \\
\hline Change in LDL $(\mathrm{mg} / \mathrm{dL})$ & $15.84(5.30)^{\ddagger}$ & $|3.7|(5.02)^{\ddagger}$ & $2.67(5.23)$ & $3.96(5.34)$ & 0.18 \\
\hline Change in triglycerides $(\mathrm{mg} / \mathrm{dL})$ & $-1.34(6.72)$ & $-7.68(6.36)$ & $-13.07(6.6 \mathrm{I})^{\ddagger}$ & $-19.87(6.8 I)^{\ddagger}$ & 0.26 \\
\hline
\end{tabular}

Notes: *Values are least-squares means (SE) adjusted for baseline age, gender, race, education, recruitment wave, medication, and baseline blood pressure or lipids value. ${ }^{\dagger}$ Differences in blood lipids change across groups (row $P$ values), ${ }^{\ddagger}$ within-groups were tested by analysis of covariance (ANCOVA) $(P<0.05)$, and $\S$ Significant across group differences were followed by pair-wise comparisons to test whether intervention groups differed significantly from the standard care group $(P<0.05)$.

Abbreviations: BP, blood pressure; HDL, high-density lipoprotein; LDL, low-density lipoprotein; SE, standard error. 


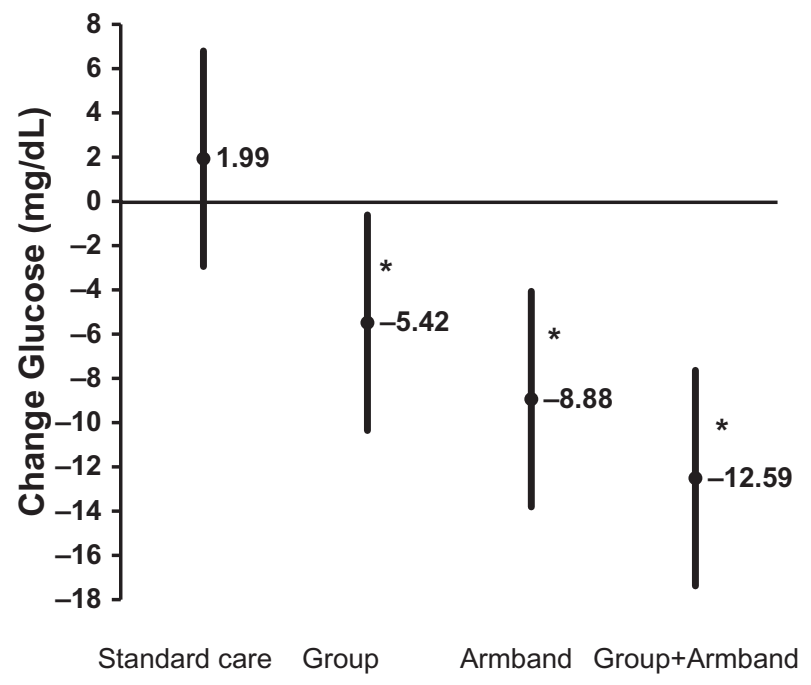

Figure 2 Mean change (least-squares mean $\pm 95 \%$ confidence interval) in fasting glucose for the standard care and intervention groups. Difference across groups were tested by analysis of covariance (ANCOVA) with adjustment for prespecified covariates (baseline age, gender, race, education, recruitment wave, and baseline glucose) among 152 participants not taking glucose medication. Significant ANCOVAs $(P<0.05)$ were followed by pair-wise comparisons to test whether intervention groups differed significantly from the standard care group.

Notes: *The P-values for pairwise comparisons of standard care with the armband, group, and group + armband were $P<0.05$ for each.

sessions in 12 weeks, and a booster session at 22 weeks plus a pedometer. At the 1-year follow up, results indicated no significant changes in TC or BP, but there was a significant decrease in $\mathrm{HbAlc}$ within both groups ${ }^{16}$ which agrees with our findings. Lastly, in the "Walking for Wellbeing in the West" study, while triglycerides and glucose were not measured, no differences were found for TC, HDL, or BP between or within the intervention or control groups. ${ }^{17}$ Overall, our findings are comparable with the existing literature. ${ }^{12,14,16,17,19,20}$ Most studies found no changes to cholesterol levels. . $^{12,16,17,19,20}$ Our findings for glycemic values agreed with one study we reviewed that dealt with technology, ${ }^{16}$ but not with findings of other studies. ${ }^{12,14,17,19}$ Even so, it is recognized that being physically active is associated with reducing glucose levels. ${ }^{29}$ We found very little change in $\mathrm{BP}$ values, which was consistent with the studies presented. ${ }^{12,14,16,17}$

The technology-based real-time monitoring used in LEAN is an example of a new type of self-monitoring. Traditional paper-based PA self-monitoring has demonstrated benefits in the past. ${ }^{12,30}$ With the advent of technological resources and the widespread availability of computers and web-based cell phones, the shift from paper to more advanced devices can provide flexibility in how data such as PA measures and energy expenditure are displayed and used for reinforcement of behavior change. Augmenting weight-loss interventions with real-time measurements and increased accessibility to PA history supports cognitive restraint from sedentary behaviors or improper food consumption by integrating constant reinforcement toward program goals. ${ }^{30}$ The value and success of using technology-based methods may be attributable to the interactive experience associated with accessing information. This methodology can support users via tailored feedback and cues to assess and enhance their PA levels while tracking progress toward personalized goals. Further study on this tailoring is needed to enhance PA behavior change and maintain adherence to healthy lifestyle programs.

\section{Physiological mechanisms}

PA is known to influence several factors that may lower the levels of fasting blood glucose. Of primary importance is increasing insulin sensitivity and decreasing insulin resistance, resulting in improved metabolic responses when shuttling nutrients for glucose storage and usage. ${ }^{31,32}$ Habitual exercise has also been shown to increase citrate synthase and cellular GLUT-4 protein expression, each of which increases the uptake of glucose into the skeletal muscle. ${ }^{33,34}$ This can directly clear glucose more effectively from the blood stream. Weight loss itself has also been linked to lower glucose levels in the blood..$^{35}$ These physiologic responses together can explain why lower levels of fasting glucose were found. Modest blood pressure reduction has been found with those participating in regular exercise, though persons who are in stage 1 or 2 hypertension may benefit more than those who are normotensive. ${ }^{36}$ Due to our population being in the latter category, we did not find great reductions in BP values. Greater improvements in these cardiometabolic risk factors may be more likely seen in those with either consistent or higher levels of energy expenditure in combination with diet interventions such as those in the HEED program materials. ${ }^{26}$

\section{Strengths and limitations}

This study had several strengths, including the randomized design, the blinding of assessment staff to group assignments, the moderate length of follow-up, the quantitative measures used to assess the outcomes, and the large proportion of African Americans, lending diversity to our study population. This study was structured to allow comparisons with 4 different conditions, allowing detailed comparisons among different treatment modalities, including historically successful and future strategies. These results have probable implications for future commercialization and community interest in a minimal contact, widely dispersible alternative to group-based weight loss campaigns, which are relatively 
expensive. Our results may stimulate new intervention approaches to increase PA, with the result of lowering fasting glucose.

Limitations include large attrition rates in the standard care group ( $48 \%$ attrition rate), though this was similar in all groups. Most of the participants in the LEAN study were female $(82 \%)$, and had a high level of education (college or above, $77 \%$ ). This limits our results to similar populations. Information on changes or end of study prescription medication for BP, lipids, or glucose was not available. This may present a concern from internal validity threats due to the confounding nature of these substances on our outcome measures. However, assumptions were made that few persons on medication would enter or exit medication therapy or have their prescription changed dramatically. Due to costs, we only measured the cardiometabolic risk factors at baseline and month 9 . We were not able to examine the relationship of the glucose, or the other values, with time. We suggest that future studies allow for several measurement points to investigate this relationship when using technology-based methods.

\section{Conclusions}

In this study of sedentary, overweight or obese men and women, all three treatments using group or armband conditions reduced fasting glucose levels when compared with standard care. No changes were found for BP or blood lipids between the standard care and treatment conditions. Our study suggests that the incorporation of armband technology into weight loss interventions can be an effective strategy to lower fasting glucose. This illustrates the value of utilizing real-time self-monitoring systems for measuring energy expenditure in future programs. Automated devices, such as the armband, can be a successful way to disseminate healthy lifestyle programs that can improve important health risk factors. This can be accomplished without group-based behavioral programs, thereby potentially reducing costs.

\section{Acknowledgments}

We thank the study participants for their dedication to advancing science. We thank the University of South Carolina student researchers, Deidre Burch, Katelyn Tambellini, and Mia Taylor, for their dedication to participant recruitment and retention. We thank GO Christmus for editorial assistance. We also thank the University of South Carolina's Clinical Exercise Research Director, Patrick Crowley; without his assistance, participant recruitment and data collection would not have been possible.

\section{Funding source/trial registration}

This study was funded by an unrestricted research grant provided by BodyMedia. This trial was registered at www. clinicaltrials.gov (No. NCT00957008).

\section{Disclosure}

The authors report no conflict of interest in this work.

\section{References}

1. Proper KI, HildebrandtVH, Van der BeekAJ, Twisk JW, Van Mechelen W. Effect of individual counseling on physical activity fitness and health: a randomized controlled trial in a workplace setting. Am J Prev Med. Apr 2003;24(3):218-226.

2. Church TS, Martin CK, Thompson AM, Earnest CP, Mikus CR, Blair SN. Changes in weight, waist circumference and compensatory responses with different doses of exercise among sedentary, overweight postmenopausal women. PLoS One. 2009;4(2):e4515.

3. Fairey AS, Courneya KS, Field CJ, et al. Effect of exercise training on C-reactive protein in postmenopausal breast cancer survivors: a randomized controlled trial. Brain Behav Immun. 2005;19(5):381-388.

4. Kasapis C, Thompson PD. The effects of physical activity on serum C-reactive protein and inflammatory markers: a systematic review. J Am Coll Cardiol. 2005;45(10):1563-1569.

5. Lokey EA, Tran ZV. Effects of exercise training on serum lipid and lipoprotein concentrations in women: a meta-analysis. Int J Sports Med. 1989;10(6):424-429.

6. US Department of Health and Human Services. 2008 physical activity guidelines for Americans. [Updated 4 November 2009]. Available from: http://www.health.gov/PAGuidelines.

7. Greenland P, Knoll MD, Stamler J, et al. Major risk factors as antecedents of fatal and nonfatal coronary heart disease events. JAMA. 2003; 290(7):891-897.

8. Bild DE, Folsom AR, Lowe LP, et al. Prevalence and correlates of coronary calcification in black and white young adults: the Coronary Artery Risk Development in Young Adults (CARDIA) Study. Arterioscler Thromb Vasc Biol. 2001;21(5):852-857.

9. Blair SN, Kampert JB, Kohl HW, et al. Influences of cardiorespiratory fitness and other precursors on cardiovascular disease and all-cause mortality in men and women. JAMA. 1996;276(3):205-210.

10. Tuomilehto J, Rastenyte D, Jousilahti P, Sarti C, Vartiainen E. Diabetes mellitus as a risk factor for death from stroke. Prospective study of the middle-aged Finnish population. Stroke. 1996;27(2):210-215.

11. Wolf PA, D'Agostino RB, Belanger AJ, Kannel WB. Probability of stroke: a risk profile from the Framingham Study. Stroke. 1991;22(3):312-318.

12. Tudor-Locke C, Bell RC, Myers AM, et al. Controlled outcome evaluation of the First Step Program: a daily physical activity intervention for individuals with type II diabetes. Int J Obes Relat Metab Disord. 2004; 28(1):113-119.

13. Ash S, Reeves M, Bauer J, et al. A randomised control trial comparing lifestyle groups, individual counselling and written information in the management of weight and health outcomes over 12 months. Int $J$ Obes(Lond). 2006;30(10):1557-1564.

14. Carr LJ, Bartee RT, Dorozynski C, Broomfield JF, Smith ML, Smith DT. Internet-delivered behavior change program increases physical activity and improves cardiometabolic disease risk factors in sedentary adults: results of a randomized controlled trial. Prev Med. 2008;46(5):431-438.

15. Norman GJ, Zabinski MF, Adams MA, Rosenberg DE, Yaroch AL, Atienza AA. A review of eHealth interventions for physical activity and dietary behavior change. Am J Prev Med. 2007;33(4):336-345.

16. De Greef K, Deforche B, Tudor-Locke C, De Bourdeaudhuij I. A cognitive-behavioural pedometer-based group intervention on physical activity and sedentary behaviour in individuals with type 2 diabetes. Health Educ Res. 2010;25(5):724-736. 
17. Baker G, Gray SR, Wright A, et al. The effect of a pedometer-based community walking intervention "Walking for Wellbeing in the West" on physical activity levels and health outcomes: a 12-week randomized controlled trial. Int J Behav Nutr Phys Act. 2010;7(1):51.

18. Polzien KM, Jakicic JM, Tate DF, Otto AD. The efficacy of a technologybased system in a short-term behavioral weight loss intervention. Obesity. 2007;15(4):825-830.

19. Bravata DM, Smith-Spangler C, Sundaram V, et al. Using pedometers to increase physical activity and improve health: a systematic review. JAMA. 2007;298(19):2296-2304.

20. Stefanick ML. Physical activity for preventing and treating obesityrelated dyslipoproteinemias. Med Sci Sports Exerc. 1999;31(11 Suppl): S609-S618.

21. Barry VW, McClain AC, Shuger S, et al. Using a technology-based intervention to promote weight loss in sedentary overweight or obese adults: a randomized controlled trial study design. Diabetes Metab Syndr Obes. 2011;4:67-77.

22. Sharma M. Behavioural interventions for preventing and treating obesity in adults. Obes Rev. 2007;8(5):441-449.

23. Clark MM, Niaura R, King TK, Pera V. Depression, smoking, activity level, and health status: pretreatment predictors of attrition in obesity treatment. Addict Behav. 1996;21(4):509-513.

24. Chobanian AV, Bakris GL, Black HR, et al. The Seventh Report of the Joint National Committee on Prevention, Detection, Evaluation, and Treatment of High Blood Pressure: the JNC 7 report. JAMA 2003; 289(19):2560-2572.

25. Blair S, Dunn A, Marcus B, Carpenter R. Active Living Every Day: 20 weeks to lifelong vitality. Champaign: Human Kinetics;2001.

26. Carpenter R, Finley C. Healthy Eating Every Day. Champaign: Human Kinetics;2005.
27. Prochaska JO, Norcross JC, DiClemente CC. Changing for good: A revolutionary six-stage program for overcoming bad habits and moving your life positively forward. New York, NY: Avon Books Inc.; 1994.

28. Bandura A. Social foundations of thought and action: A social cognitive theory. Englewood Cliffs, NJ: Prentice Hall; 1986.

29. Albright A, Franz M, Hornsby G, et al. American College of Sports Medicine position stand. Exercise and type 2 diabetes. Med Sci Sports Exerc. 2000;32(7):1345-1360.

30. Butryn ML, Phelan S, Hill JO, Wing RR. Consistent self-monitoring of weight: a key component of successful weight loss maintenance. Obesity(Silver Spring). 2007;15(12):3091-3096.

31. van Baak MA, Borghouts LB. Relationships with physical activity. Nutr Rev. 2000;58(3 Pt 2):S16-S18.

32. Borghouts LB, Keizer HA. Exercise and insulin sensitivity: a review. Int J Sports Med. 2000;21(1):1-12.

33. Kraniou GN, Cameron-Smith D, Hargreaves M. Effect of short-term training on GLUT-4 mRNA and protein expression in human skeletal muscle. Exp Physiol. 2004;89(5):559-563.

34. Ren JM, Semenkovich CF, Gulve EA, Gao J, Holloszy JO. Exercise induces rapid increases in GLUT4 expression, glucose transport capacity, and insulin-stimulated glycogen storage in muscle. $J$ Biol Chem. 1994;269(20):14396-14401.

35. Anderson JW, Konz EC. Obesity and disease management: effects of weight loss on comorbid conditions. Obes Res. 2001;9 Suppl 4: 326S-334S.

36. Blumenthal JA, Sherwood A, Gullette ECD, et al. Exercise and weight loss reduce blood pressure in men and women with mild hypertension: effects on cardiovascular, metabolic, and hemodynamic functioning. Arch Intern Med. 2000;160(13):1947-1958.

\section{Publish your work in this journal}

Diabetes, Metabolic Syndrome and Obesity: Targets and Therapy is an international, peer-reviewed open-access journal committed to the rapid publication of the latest laboratory and clinical findings in the fields of diabetes, metabolic syndrome and obesity research. Original research, review, case reports, hypothesis formation, expert opinion and commentaries are all considered for publication. The manuscript management system is completely online and includes a very quick and fair peer-review system, which is all easy to use. Visit http://www.dovepress.com/testimonials.php to read real quotes from published authors. 